\title{
Finite element modeling of the effect of tool rake angle on cutting force and tool temperature during high speed machining of AISI 1045 steel
}

\begin{abstract}
A finite element model (FEM) of an orthogonal metal-cutting process is used to study the influence of tool rake angle on the cutting force and tool temperature. The model involves Johnson-Cook material model and Coulombôs friction law. A tool rake angle ranging from $0^{\circ}$ to $20^{\circ}$ and a cutting speed ranging from 300 to $600 \mathrm{~m} / \mathrm{min}$ were considered in this simulation. The results of this simulation work are consistent optimum tool rake angle for high speed machining (HSM) of AISI 1045 medium carbon steel. It was observed that there was a suitable rake angle between $10^{\circ}$ and $18^{\circ}$ for cutting speeds of 300 and $433 \mathrm{~m} / \mathrm{min}$ where cutting force and temperature were lowest. However, there was not optimum rake angle for cutting speeds of 550 and $600 \mathrm{~m} / \mathrm{min}$. This paper can contribute in optimization of cutting tool for metal cutting process.
\end{abstract}

Keyword: Finite element modeling; High speed machining; Rake angle 